\title{
Impact of ICT on entrepreneurial self-efficacy in emerging economy: Sustaining lock-down during COVID-19 pandemic
}

\author{
Taiba Sardar ${ }^{\mathrm{a}, *}$, Zeng Jianqiu ${ }^{\mathrm{a}}$, Muhammad Bilal ${ }^{\mathrm{a}}$ and Nausheen Syed ${ }^{\mathrm{b}}$ \\ ${ }^{a}$ School of Economics and Management, Beijing University of Posts and Telecommunications, Beijing, China \\ ${ }^{\mathrm{b}}$ Department of Business Administration, Government College Women University, Faisalabad, Pakistan
}

Received 23 July 2020

Accepted 22 September 2020

\begin{abstract}
.
BACKGROUND: COVID-19 affected business in Pakistan and micro-entrepreneurs started struggling. ICT facilitates economic competitiveness and help in sustaining long-term economic growth during and after pandemic.

OBJECTIVE: This article investigates the impact of information communication technology (ICT) on entrepreneurial self-efficacy (ESE), social networking (SN) and facilitation to micro-entrepreneurs, during COVID-19 pandemic in Pakistan. METHOD: We used Technology Acceptance Model (TAM) in this work. The original TAM constructs of ease of use and usefulness were tested, and TAM was extended to ICT to study the further outcomes. Data sets were collected online from 398 microentrepreneurs and further analysed by using the Structural Equation Modelling (SEM).

RESULTS: The results indicate that survival of micro-entrepreneurs can be achieved through ICT as it is a strong variable which affects social capital building, bridging and self-efficacy, both directly and indirectly. The entrepreneurial activity can be increased through ICT and entrepreneurs can sustain the implications of lock-downs.

CONCLUSION: The findings suggested that ICT usage by micro-entrepreneurs during COVID-19 pandemic was influenced by micro-entrepreneurs' perceptions, of ease of use and usefulness. ICT had direct influence on entrepreneurial self-efficacy and social networking. The theoretical and practical implications of the results are also given.
\end{abstract}

Keywords: Information communication technology (ICT), technology acceptance model (TAM), entrepreneurial self-efficacy, ICT facilitation, COVID-19

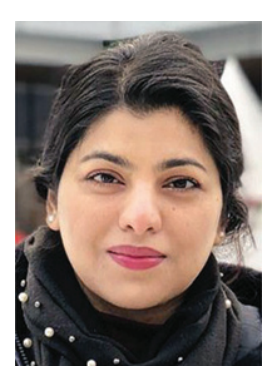

Taiba Sardar is a Ph.D. Scholar at the School of Economics and Management at the Beijing University of Posts and Telecommunications (BUPT), Beijing, China. She completed MBA (Professional Degree) from Beijing Technology and Business University (BTBU), Beijing, China in 2015. Her research interests concern Entrepreneurship, Information Communication Technology (ICT) and Social Networking.

\footnotetext{
${ }^{*}$ Corresponding author: Taiba Sardar, School of Economics and Management, Beijing University of Posts and Telecommunications, Beijing, China. Tel.: +86 13501725524; E-mail: taibasardar@gmail.com.
}

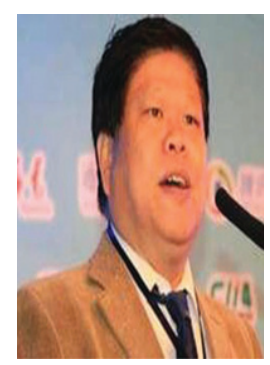

Professor Zeng Jianqiu obtained his Ph.D. from Cambridge University, UK. He is a doctoral adviser at the School of Economics and Management at the Beijing University of Posts and Telecommunications (BUPT), Beijing, China. He is also the Director of Information Economy and Competitiveness Research Center. 


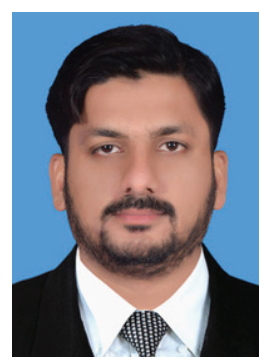

Muhammad Bilal is a $\mathrm{PhD}$ Scholar in Marketing at the School of Economics and Management, Beijing University of Posts and Telecommunications, Beijing, China. He received his Master's (MBA) in Marketing from the NCBA and E Lahore, Pakistan. He has almost seven years of industry experience in Marketing Department. Before commencing his Doctoral research, he also worked as a Visiting Lecturer in Marketing at the NCBA and E, Pakistan. His current areas of interest include E-WOM, E-marketing, E-commerce, Social Commerce and Consumer Behavior.

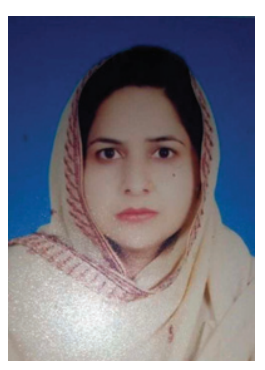

Dr. Nausheen Syed completed her Ph.D. in Corporate Management from Beijing Jiaotong University, Beijing, China. She is currently working as an Assistant Professor and the Head of Department of Business Administration, at the Government College Women University Faisalabad. She has seven years teaching experience in different universities of Pakistan. Her research interest includes Human Resource Management, Marketing Management, Knowledge Management and Leadership.

\section{Introduction}

The outbreak of severe acute respiratory tract coronavirus-2 (SARS-CoV-2) in Wuhan in late December (2019) caused calamitous consequences in 213 countries (territories) across the world and 2 international conveyances [1]. The World Health Organization (WHO) declared international public health emergency on 30th January, 2020 [2, 3], as human-to-human transmission of the coronavirus (COVID-19) is extremely fast which poses significant threat to the public health safety around the world. The immediate implication of COVID-19 was socioeconomic chaos, which includes cancellation of flights, sports, public gatherings, religious, political and cultural activities [4]. According to the United Nations Educational, Scientific and Cultural Organization (UNESCO), schools and universities in 193 countries (99.4\% of the population) announced local and national closures [5]. The COVID-19 has not only threatened human mankind around the world but it has also posed immediate challenges for those institutions which are providing services to the affected communities. The local institutions are facing existential threats during the collapse of livelihoods [6].
This health crisis grew in almost every country around the world but it is continuously growing in the developing countries such as Pakistan, where health care institutions are not strong (weak) and fragmented. The number of COVID-19 patients is increasing exponentially [7] after the lock-down is lifted, and now, it is a big challenge for health care institutions to save lives from grave threat of COVID19. Connected with this is another important question that how will micro-entrepreneurs, who are backbone of economic development in Pakistan, survive during and after COVID-19 pandemic. So far, there is no study available which focus on the survival of those micro-entrepreneurs, who suffered during the COVID-19 pandemic therefore, we selected this topic for our research.

We mainly focus on the survival of microentrepreneurs during and after COVID-19 pandemic, through the use of ICT because it facilitates economic competitiveness and sustain long-term economic growth [8]. In general, information communication technology is nothing but unified communications that also includes integrated telecommunications for example, mobile phones, computers (including laptops), software and other systems which enable users to send and receive information easily. In the current digital world, almost all individuals interact with each other through personal mobile phones, computers, social media and other networking applications, which fall under the umbrella of ICT $[9,10]$. There is an indirect relationship between ICT adoption and micro-entrepreneurs, for their support through moderator (entrepreneurial self-efficacy) and mediator (social networking). Therefore, we emphasize the theoretical perspective of TAM in this research work, to check the primary TAM constructs such as usefulness and the ease of use. Our work is convergent on the survival of micro-entrepreneurs in Pakistan during and after COVID-19 pandemic, by developing a linkage between TAM and the effect of ICT adoption with entrepreneurial self-efficacy, establishing and up keeping social networking, and multi-fact aspects of facilitation.

The manuscript is comprised of 9 sections. The literature review is presented in Section 2. The hypothesis and model are discussed in Section 3. In Section 4, the methodology that includes instrument (tools) and analysis method, is given. In Section 5, the important findings are given. The Section 6 of the manuscript is dedicated to discussion. In Section 7, implications of the study, both theoretical and practical, are given. The limitations of this work 
and future possibilities are given in the Section 8 . The conclusion of our work is given in the last Section 9.

\section{Literature review}

\subsection{COVID-19 in Pakistan}

The first two confirmed cases of COVID-19 were reported in Islamabad and Karachi, by the Federal Health Minister on 26 February 2020. After 15 days, 14 cases were reported in Sindh, 5 in Gilgit Baltistan and 1 in Balochistan with 471 suspected samples. The imported cases of COVID-19 had travel history to Pakistan's nearest neighbour, Iran [11-13]. As a front line defence to prevent and limit the spread of coronavirus, lockdown was announced in the country however, the starting date varied from province to province. Sindh started lock-down on 14th March, under the Orders No. SO(3-1)/HD/8-1/(04)/2020-Corona and $\mathrm{SO}(\mathrm{J}-1) / \mathrm{HD} / 8-1(04) / 2020-C o r o n a$, which were issued under Sindh Epidemic Diseases Act 2014. Azad Kashmir started lock-down on 16th March under the Pandemic Diseases Control Act 1981. Punjab started observing lock-down on 23rd March after a special order, which was issued under section 144 of the National Code of Criminal Procedure 1898. Balochistan observed lock-down from 23 March by issuing special order (NOSO(Judl:)8(31)2020/545630), under Section 144 of the Code of Criminal Procedure 1898 [14].

Just after the announcement of lock-down, public transport and shopping malls were closed to restrict the mobility of people. Furthermore, flights operation (both domestic and international), public gatherings, academic (both teaching and research), sports, religious, political and social activities were cancelled. Only essential services remained open such as pharmacies etc. The human-to-human transmission of COVID-19 was slowed down during the first two weeks of one-month complete lock-down but the unknown carriers of the virus were not traced and identified. During the one-month complete lockdown, all industries remained closed and all sorts of imports and exports were seized. The purposefulness of complete lock-down was partially fulfilled and later, complete lock-down was converted to smart lock-down (partial lock-down). The economic loss in one-month lock-down was huge for a developing country like Pakistan therefore, smart lock-down was introduced which was to be enforced in different stages.

The COVID-19 claimed thousands of lives in Pakistan but at the same time, it also claimed economic capacity from daily wagers, sole proprietors and micro-entrepreneurs, as their income and in some cases source of income collapsed during one-month lock-down. Most of the daily wagers were forcefully removed from their workplace and micro-entrepreneurs lost their customers. So far, there is no study available which covers that how micro-entrepreneurs have survived during COVID19 pandemic. Therefore, we discuss this topic in detail.

\subsection{Facilitating role of ICT adoption to micro-entrepreneurs}

According to Ayyagari et al., the fundamental challenge of low and middle income countries is to create good jobs in high-productivity sector with good working condition and micro-enterprises have the capacity to do this [15]. Jamak and co-authors also reported that micro-enterprises are developed in the developing countries to eliminate poverty. Furthermore, these enterprises offer employment opportunities and income opportunities to supplement household income [16]. According to Kureshi et al., micro-enterprises share fundamental part of industrial employment and manufacturing exports in Pakistan. Micro-enterprises comprising of less and five and(or) ten persons contribute to $99 \%$ of total business and manufacturing [17]. But, the literature related to micro-enterprises in Pakistan is limited because of lack of information about adoption and growth of business. Furthermore, the organizations (firms) which offer online business are also limited [18].

Kossai and Piget reported the increasing usage of information and communication technologies as one of the prominent trends of last thirty years. The performance of many developed countries is linked to the use of information communication technology (ICT) [19]. The easy access to knowledge and information via internet has created endless opportunities and the use of ICT has rapidly spread to developing and emerging countries which is opening new prospects of growth [20-24]. Sardar and co-authors also reported the revolution of ICT adoption in Pakistan for female microentrepreneurs. In their study, the influence of information communication technology on the personal and professional development of 
entrepreneurs was obvious [25]. Hence, the use of TAM in this work supports ICT adoption for microentrepreneurs in terms of ease of use and perceived usefulness. Both the perceived usefulness and ease of use have direct impact on the technology use decisions [26]. Furthermore, TAM is the best theoretical foundation to study technology acceptance and technology related outcomes [27]. ICT as a tool for support to entrepreneurs is already clear in previous literature. This research work explores the intermediate variables of entrepreneurial self-efficacy and social networking associated with ICT adoption, as an engine to facilitate micro-entrepreneurs.

\subsection{Information communication technology (ICT)}

According to Sani Naivinit, a large variety of technologies fall under the umbrella of Information Communication Technology (ICT) which help people in connecting with each other from different locations [28]. ICT creates globalization which improves the structure and performance of organizations. It also influences the strategies of business and the management functions of the human resource [29]. ICT technologies such as mobile apps and social networking create new opportunities of knowledge in information communication technology mediated spaces for individuals. They participate in social conversations, develop new content and build relevant connections [30, 31]. According to Kundi and Shah, online business has more opportunities in Pakistan [32] and ICT plays a significant role in human development itself [33]. Donath and Boyd hypothesized that by using information communication technology (ICT), individuals gain information from loose connections and resources by putting less effort and at low cost [34].

Sardar and co-authors also mentioned that ICT has brought a revolutionary change in Pakistan for small and medium-sized enterprises [25]. Pakistan is the developing country but it has invested a lot in information technology to cope up with the digital world therefore, the use of social and mobile technologies is growing in Pakistan. According to Rauniar et al., the increasing usage of social and mobile technology is due to the ease of use and the effectiveness, in coping up with the individual's requirement of connecting with others, for learning and sharing information [35]. The direct impact of ICT is increase in productivity and quality at low operating cost. Further, response to customers and other business partners is easy. Malone et al., reported that information communication technology reduces the coordination costs which leads to an overall shift towards small firms and proportionally extra use of markets [36].

According to Rahman and co-authors, ICT has obvious impact on the personal and professional development of micro-entrepreneur [37]. Furthermore, the modern information communication technology tools such as personal-computers, social networking apps, internet and mobile-phones [38] etc. support the ease of use and user adoption.

\section{Hypothesis and model}

The major constructs of current research work such as ICT adoption, entrepreneurial self-efficacy (ESE), social networking (SN) and facilitation to micro-entrepreneurs, comprise our model as shown in Fig. 1. Furthermore, the detail of each construct and hypotheses used for testing and validating each variable, is given in the coming sections.

\subsection{ICT adoption}

COVID-19 has adversely affected business in Pakistan. ICT adoption will help micro-entrepreneurs to sustain during and after pandemic. Furthermore, they can reap the benefits of technology and regain economic stability and growth. According to Solow, computer age can be used for productivity which means that in the current globalized world, ICT innovative and technological changes determine the productivity, capability, capacity and growth of countries to achieve goals and reap benefits [39]. Hollenstein also reported that ICT is a vehicle of innovation and by using ICT technologies, productivity can be increased [40]. In another recent article, Javed and co-authors reported that ICT adoption by entrepreneurs enhances performance [41]. Bvuma and Marnewick have also supported ICT adoption for improved livelihood of small, medium and microenterprises to achieve growth and development [42]. Rauniar and co-authors also reported that ICT adoption meets individual's demand of connecting with others and sharing information with ease of use and effectiveness [43].

The authors in ref. [44] discussed the gold-rush response of organizations towards information communication technology and suggested that innovative ICT tools are enablers for sales person to accomplish (exploit) formal and informal networks. They 


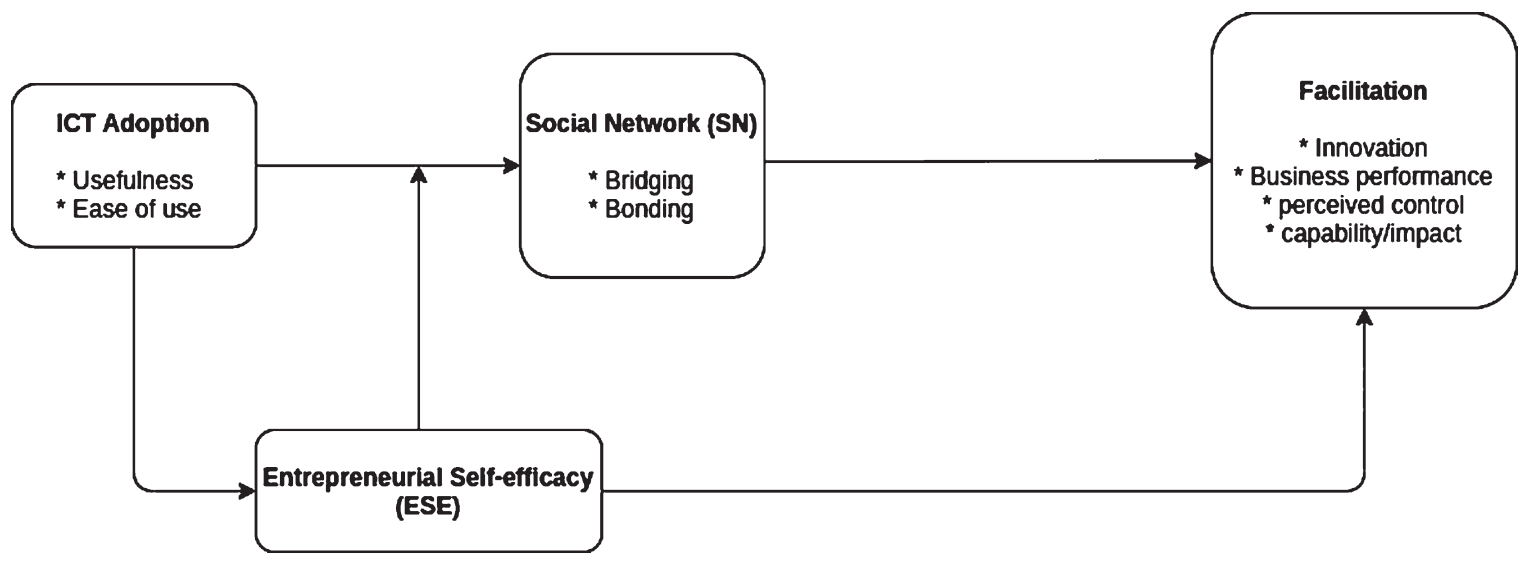

Fig. 1. Constructs of the research model.

also proposed a theoretical framework that described service behavior to create value. Victoria and coauthors also studied the influence of information communication technology (ICT) on entrepreneurial self-efficacy (ESE), social capital and empowerment for female micro-entrepreneurs of developing countries [45]. Bidwell et al., reported that entrepreneurial self-efficacy and ability of micro-entrepreneurs is improved through information communication technology [46]. Beninger and co-authors investigated the positive impact of ICT tools such as social media, on the personal and professional lives of female entrepreneurs [47].

It is aforementioned that we have employed the technology acceptance model in our work and according to the model, the perceived ease of use and usefulness are straightforward determinants of the people's intentions [48]. Furthermore, the model suggests that ICT ease of use significantly influence perceived usefulness, provided it is easy to use [49]. Some other studies have also supported the perception of ICT adoption and usefulness [50, 51]. Hence, the hypothesis is postulated in the following way:

H1a: ICT adoption perceived usefulness affects positively to facilitate direct selling of microentrepreneurs.

H1b: ICT adoption ease of use positively effects direct selling of micro-entrepreneurs.

\subsection{Entrepreneurial self-efficacy (ESE) and social networking $(\mathrm{SN})$}

Bandura and Saleem et al., provided the definition of entrepreneurial self-efficacy (ESE) as individuals' belief in their ability to influence external factors to achieve a desired goal or outcome [52, 53]. McGee and co-authors also provided a similar definition of ESE, as the belief which individuals have in their abilities to establish a successful new venture [54]. ESE is extremely essential for entrepreneurs as it determines their intention to become a successful entrepreneur. It also checks their abilities to transform intentions to actions which leads to personal success [55]. Entrepreneurial self-efficacy is connected with personality of entrepreneurs. The empirical findings signify that personality is a necessary determinant of occupational choices and that the personality characteristics are important in describing self-employment and entrepreneurship [56]. The self-efficacy increases with time because the personality of individuals' gets more persistent [57]. Hence, it is implicit that the performance or outcome of individual's solely depends on personality [58]. Self-efficacy being an internal characteristic of individuals' directly influences the functionality of technology and outcome [59].

Along with self-efficacy, there are many advantages of strong ties in providing access to the required resources [60]. According to Kadam and Ayarekar, social networking directly influences the behavior of micro-entrepreneurs in the market [61]. According to refs. [62, 63], micro-entrepreneurs can get better access to target audience through social networking and they can remain in-tune to varying wants and needs. Furthermore, they can improve communication with potential customers. Mukoolwe and Korir reported that social networking can provide more effectual marketing, new communication, more distribution (dispersion) channels, shorter time to market, online technical support and interactive 
community [64]. The refs. [65, 66] also reported that buying behaviors of customers have shifted from traditional to digital platforms. Now, customers are more inclined towards convenience, assertiveness and control over buying. Park also reported the usefulness of social networking platforms in any business environment for opportunity recognition [67]. The social media platforms via internet have greatly improved connectivity with new emerging markets, supply chain and customers [68]. The recent scenario is also supported by the Coleman's theory of network closure [69], which states that in the strong tie network, the contacts of the entrepreneur are connected with small or no structural holes [70]. Hence, the hypothesis is postulated in the following way:

H2a: ICT adoption perceived usefulness positively effects the entrepreneurial self-efficacy (ESE).

H2b: ICT adoption perceived ease of use positively effects the entrepreneurial self-efficacy (ESE).

H2c: ICT adoption perceived usefulness positively effects the social network bridging (moderated by ESE).

H2d: ICT adoption perceived ease of use positively effects the social network bridging (moderated by ESE).

H2e: ICT adoption perceived usefulness positively effects the social network bonding (moderated by ESE).

H2f: ICT adoption perceived ease of use positively effects the social network bonding (moderated by ESE).

\subsection{Facilitation to micro-entrepreneurs}

During COVID-19 pandemic, small businesses and micro-entrepreneurs are facing major obstacles. They are struggling to keep up with time. According to refs. [71, 72], during struggling time, business policies (strategies) should be revisited (rethink). One possible solution is to use information communication technology (ICT) which allows to improve innovation levels because ICT technologies are innovation facilitator for products and processes. According to Aguilera and co-authors, in this way micro-entrepreneurs can improve their competitiveness and performance level which allow them to face multiple challenges of the environment. Furthermore, they remain in the global markets highly competitive [73]. Some other authors also supported the facilitating role of information communication technology and mentioned that small and medium enterprises should incorporate (use) information communication technologies as essential business strategy, to propel efficiency, improve competitiveness [74], raise productivity [75] and gain client, employee plus supplier satisfaction [76]. During pandemic in Pakistan, we propose that entrepreneurial self-efficacy, SN bridging and bonding will facilitate micro-entrepreneurs in improving business. Therefore, we postulate our hypothesis in the following way:

H3a: SN bridging positively effects the facilitation of micro-entrepreneurs if operated by innovation.

H3b: SN bridging positively effects the facilitation of micro-entrepreneurs operated by business performance.

H3c: SN bridging positively effects the facilitation of micro-entrepreneurs if operated by perceived usefulness.

H3d: SN bridging positively effects the facilitation of micro-entrepreneurs if operated by capability/impact.

H4a: SN bonding positively effects the facilitation of micro-entrepreneurs if operated by innovation.

H4b: SN bonding positively effects the facilitation of micro-entrepreneurs operated by business performance.

H4c: SN bonding positively effects the facilitation of micro-entrepreneurs if operated by perceived usefulness.

H4d: SN bonding positively effects the facilitation of micro-entrepreneurs if operated by capability/impact.

H5a: ESE positively effects the facilitation of micro-entrepreneurs if operated by innovation.

H5b: ESE positively effects the facilitation of micro-entrepreneurs if operated by business performance.

H5c: ESE positively effects the facilitation of micro-entrepreneurs if operated by perceived usefulness. 
H5d: ESE positively effects the facilitation of micro-entrepreneurs if operated by capability/impact.

\section{Methodology}

The purposefulness of this work is to study the facilitating role of information communication technology in sustaining lock-down during COVID-19 pandemic in Pakistan, through Technology Acceptance Model (TAM) by considering entrepreneurial self-efficacy, ease of use and perceived usefulness as major determinants. We explored four major constructs such as ICT adoption, entrepreneurial self-efficacy, social networking and facilitation. ICT adoption was studied by using two variables such as usefulness and ease of use. Social networking was implemented through bonding and bridging. Facilitation was operated by innovation, business performance, perceived usefulness and capability/impact as shown in Fig. 2.

To check the constructs of the research model, multi-term measures were used. A rigorous process was adopted including literature review, survey items evaluation and pilot testing of survey. Data sets were collected from twin cities (Rawalpindi and Islamabad) through convenience based sampling technique. The micro-entrepreneurs who were running small business as sole proprietors were target sample of our research study. A total of 433 out of 480 questionnaires were received back however,
398 were eligible for the final analysis. The data sets were collected from $25^{\text {th }}$ March, 2020 to $10^{\text {th }}$ June, 2020. In addition, the constructs of our research model and measures were developed according to the context and culture of Pakistan. Table 1 shows the demographic information of respondents and Table 2 summarizes ICT adoption of respondents by device and apps.

\subsection{Methods and tools}

The entire scale items of the construct were adopted from previous research and measured using a five-point Likert scale. Perceived usefulness on three items, adapted from ref. [77]. Ease of use on four items as in ref. [78]. Perceive Control (two items) and Impact (three items) were adopted from ref. [79]. Innovation was measured on seven items, adopted from ref. [80]. Bridging was measured on seven items and Bonding was measured on three items, adopted from ref. [81]. ICT use to support direct selling was measured on six items, adopted from ref. [82].

\subsection{Analysis method}

Structural equation modelling (SEM) was used for the testing of the hypothesis and to evaluate the relationships of latent (factors) and manifest variables (items). Statistical packages for social science (SPSS) 22.0 and AMOS 22.0 were used for data entry and analysis, created by IBM. The purpose of SEM was to estimate the structured coefficient relationships in

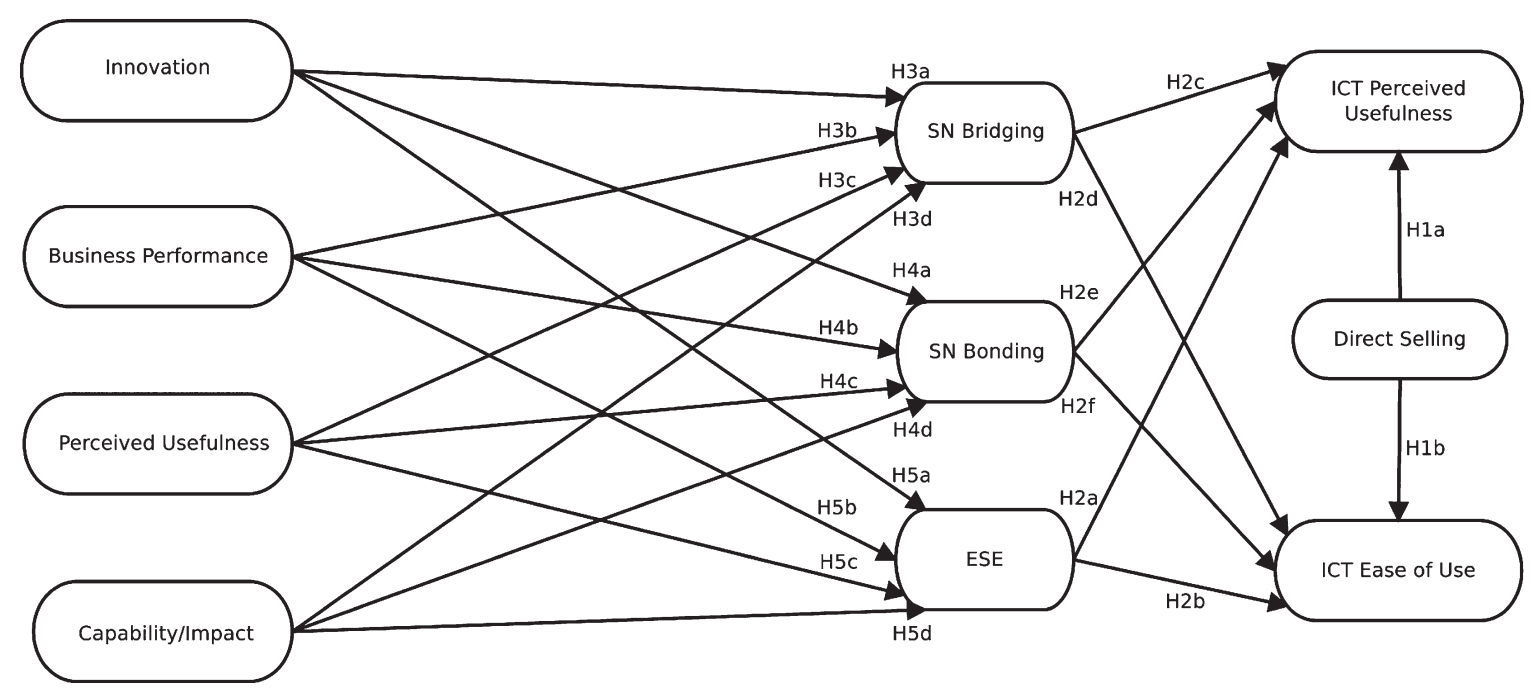

Fig. 2. Research scheme. 
Table 1

Demographic information of respondents

\begin{tabular}{|c|c|c|}
\hline Description & Frequency & Percent \\
\hline \multicolumn{3}{|c|}{ What is your age group? } \\
\hline $15-25$ & 38 & 9.5 \\
\hline $26-35$ & 78 & 19.5 \\
\hline $36-45$ & 112 & 28.1 \\
\hline $46-55$ & 95 & 23.8 \\
\hline $56-65$ & 35 & 8.7 \\
\hline 65 & 18 & 4.5 \\
\hline N/A & 22 & 5.5 \\
\hline \multicolumn{3}{|c|}{ What is your product or services? } \\
\hline Grocery store & 88 & 22.1 \\
\hline $\begin{array}{l}\text { Men and women } \\
\text { clothes (un-stitched }\end{array}$ & 67 & 16.8 \\
\hline $\begin{array}{l}\text { Kids ready-made } \\
\text { garments }\end{array}$ & 50 & 12.56 \\
\hline Book store & 32 & 8 \\
\hline Household stuff & 62 & 15.5 \\
\hline Cosmetics & 38 & 9.54 \\
\hline Bakery & 30 & 7.53 \\
\hline General store & 31 & 7.7 \\
\hline \multicolumn{3}{|c|}{ What is your average monthly income? } \\
\hline Rs. $10000-25000$ & 40 & 10.05 \\
\hline Rs. $20000-35000$ & 60 & 15.07 \\
\hline Rs. $35000-50000$ & 83 & 20.85 \\
\hline Rs. $50000-65000$ & 120 & 30.15 \\
\hline Rs. $65000-80000$ & 52 & 13.06 \\
\hline Rs. $80000-100000$ & 33 & 8.29 \\
\hline N/A & 10 & 2.51 \\
\hline \multicolumn{3}{|c|}{ Are you the sole earner in your family? } \\
\hline Yes & 280 & 70.35 \\
\hline No & 105 & 26.3 \\
\hline N/A & 13 & 3.2 \\
\hline \multicolumn{3}{|c|}{ Do you have another source of income or other business? } \\
\hline Yes & 63 & 15.8 \\
\hline No & 305 & 76.6 \\
\hline N/A & 30 & 7.5 \\
\hline
\end{tabular}

the structural equation model. Overall, the measures of fit indices were used for the assessment of the structural model. Hence, the values indicate that the measurement model is deemed to be fit.

\section{Results}

\subsection{Measurement model analysis}

The convergent validity and reliability were assessed on the basis of three metrics such as
Table 2

ICT adoption of respondents by device and apps

\begin{tabular}{lc}
\hline ICT device & Usage (in percentage) \\
\hline Smartphone & 98.5 \\
Tablets & 62.9 \\
Laptops & 32.2 \\
Desktops & 14.2 \\
Apps & \\
WhatsApp & 97.5 \\
Instagram & 85.4 \\
Facebook & 78.9 \\
YouTube & 21.3 \\
Twitter & 16.6 \\
LinkedIn & 12.6 \\
\hline
\end{tabular}

Cronbach's alpha, composite reliability and average variance extracted. Table 3 tabulates the entire values of the above mentioned metrics. All values of AVE are greater than 0.591 , which implies the convergence of the measurement items on the same construct. Cronbach's alpha and CR values of all variables were greater than 0.70 , which shows nothing but an internal consistency amongst the measurement items. Hair and co-authors [83] reported that the convergent validity should be measured on the basis of three conditions, that is, all measurement items loading should be greater than 0.70 , Cronbach's alpha must be greater than 0.70 and CR of each construct should be greater than 0.80 . The findings of current work showed that all values were greater than the threshold and therefore, supported the convergent validity of the measurement. The sampling adequacy was tested through Kaiser-Meyer-Olkin (KMO) test. The calculated values by using the KMO test were greater than 0.7 and the threshold for KMO is 0.5 , which generally means strong empirical support in terms of reliability and validity of the latent constructs in hypothesized model of this study.

Furthermore, the method introduced by Fronell and Larcker [84] was used to assess the discriminant validity. In a research model, the square root of AVE between a construct and its measures must be greater than the correlations between the construct and any other construct of the model. It was noted that each square root of AVE of each construct was greater than the inter correlations with another construct. The result is tabulated in Table 4.

The primary factor structure was assessed and finalized by applying EFA. Furthermore, CFA was applied for the classification of latent variables to assess the research model, its hypotheses and validity. 
Table 3

Reliability and convergent validity

\begin{tabular}{lcccccccc}
\hline Constructs & Items & Means & SD & Item Loading & CR & AVE & Cronbach's & KMO \\
\hline Perceived Usefulness & 3 & 3.351 & 0.613 & $0.74-0.85$ & 0.854 & 0.681 & 0.991 & 0.76 \\
Perceived Ease of Use & 4 & 3.065 & 0.541 & $0.76-0.89$ & 0.807 & 0.672 & 0.954 & 0.79 \\
Innovation & 7 & 3.442 & 0.741 & $0.75-0.91$ & 0.813 & 0.665 & 0.843 & 0.73 \\
Business Performance & 6 & 4.234 & 0.545 & $0.77-0.94$ & 0.754 & 0.692 & 0.913 & 0.71 \\
Perceived Control & 2 & 3.054 & 0.746 & $0.83-0.92$ & 0.833 & 0.677 & 0.875 & 0.69 \\
Impact & 3 & 4.301 & 0.964 & $0.76-0.92$ & 0.889 & 0.689 & 0.985 & 0.78 \\
Bridging & 7 & 3.432 & 0.727 & $0.79-0.87$ & 0.821 & 0.632 & 0.921 & 0.79 \\
Bonding & 3 & 3.132 & 0.626 & $0.73-0.88$ & 0.891 & 0.601 & 0.951 & 0.76 \\
Self-Efficiency & 5 & 3.542 & 0.672 & $0.75-0.86$ & 0.831 & 0.661 & 0.902 & 0.77 \\
ICT use to support direct selling & 6 & 3.043 & 0.927 & $0.76-0.92$ & 0.881 & 0.657 & 0.919 & 0.78 \\
\hline
\end{tabular}

Table 4

Discriminant validity and common method bias

\begin{tabular}{|c|c|c|c|c|c|c|c|c|c|c|c|c|c|}
\hline Constructs & $\mathrm{PU}$ & PEOU & IN & $\mathrm{BP}$ & $\mathrm{PC}$ & IM & $\mathrm{BG}$ & BG & SE & ICT & Eigen values & $\%$ of variance & Cumulative $\%$ \\
\hline PU & 0.755 & & & & & & & & & & 2.43 & 28.57 & 28.57 \\
\hline $\mathrm{OU}$ & $0.213 * *$ & 0.831 & & & & & & & & & 2.19 & 23.45 & 52.02 \\
\hline IN & $0.342 *$ & $0.331 * * *$ & 0.776 & & & & & & & & 2.67 & 15.31 & 67.33 \\
\hline $\mathrm{BP}$ & $0.221 * *$ & $0.403 * *$ & 0.416 & 0.881 & & & & & & & 1.42 & 10.37 & 77.07 \\
\hline $\mathrm{PC}$ & $0.352 * * *$ & $0.415^{* *}$ & $0.350^{*}$ & $0.596^{* *}$ & 0.803 & & & & & & 2.31 & 8.28 & 85.98 \\
\hline IM & $0.157 * *$ & $0.495 * * *$ & $0.351 * *$ & $0.441 * *$ & $0.113^{*}$ & 0.819 & & & & & 1.76 & 5.08 & 91.06 \\
\hline BG & $0.432 * *$ & $0.303 * * *$ & $0.451 * *$ & $0.343^{* *}$ & $0.223^{*}$ & 0.374 & 0.833 & & & & 2.2 & 4.08 & 95.14 \\
\hline BG & $0.535^{* *}$ & $0.195 * * *$ & $0.511 * *$ & $0.531 * *$ & $0.313^{*}$ & 0.394 & 0.545 & 0.894 & & & 2.56 & 2.01 & 97.15 \\
\hline SE & $0.174 * *$ & $0.695 * * *$ & $0.979 * *$ & $0.641 * *$ & $0.413^{*}$ & 0.212 & 0.11 & 0.551 & 0.868 & & 1.97 & 1.21 & 98.36 \\
\hline ICT & $0.609 * *$ & $0.795 * * *$ & $0.598 * *$ & $0.671 * *$ & $0.103 *$ & 0.645 & 0.771 & 0.71 & 0.298 & 0.848 & 2.78 & 1.64 & 100 \\
\hline
\end{tabular}

Few items were eliminated for better representation of data which improved the goodness of fit through EFA and CFA. Furthermore, factor structure was extracted from EFA to improve the overall model fitness by applying CFA. All values of CFA analysis meet the threshold value which indicates that $\mathrm{CMIN} / \mathrm{df}=2.43, p<0.005$, GFI $=0.93, \mathrm{CFI}=0.90$, AGFI $=0.89, \mathrm{NFI}=0.97$, RMSEA valued 0.07 and $\mathrm{RMR}=0.5$, represent satisfactory model fit indices (see Table 5).

\subsection{Structural model results}

The hypotheses were tested with respect to the ICT ease of use and usefulness for the analysis as shown in Fig. 3 of the structural model.

The hypotheses (H1a, H1b) suggested that the high levels of ICT ease of use and usefulness will depict a positive-relationship with ICT use, to support the direct selling activity. The path relationships between ICT ease of use and usefulness $(\beta=0.321$, $p<0.005$ ), and ICT usefulness and ICT degree of use $(\beta=0.432, p<0.005)$ were all positive and significant. Hence, the hypothesized relationships were supported.

The hypotheses $\mathrm{H} 2 \mathrm{a}$ and $\mathrm{H} 2 \mathrm{~b}$ suggested that ICT usefulness and ease of use would impact positively on the entrepreneurial self-efficacy (ESE). The path relationship between ICT usefulness, ease of use and entrepreneurial self-efficacy was found positive and significant with coefficient value $(0.234, p<0.000)$, $(0.121, p<0.005)$ respectively. For moderation $2 \mathrm{c}$, $2 \mathrm{~d}, 2 \mathrm{e}$ and $2 \mathrm{f}$ put forward that the self-efficacy of microentrepreneurs will positively moderate the relationships between usefulness, ease of use of information communication technology and social networking ( $\mathrm{SN}$ ) bridging and bonding. The moderated relationship between usefulness of information communication technology and social networking $(\mathrm{SN})$ bridging was supported and in the right direction $(\beta=0.342, p<0.005)$. The relationship between ease of use of ICT use and bridging was supported and in the right direction $(\beta=0.434, p<0.005)$. The moderated relationship between usefulness and ICT 
Table 5

Results of model fit

\begin{tabular}{lcccccccc}
\hline Fit & CMIN/df & $P$-value & RMSEA & CFI & GFI & AGFI & NFI & RMR \\
\hline Recommend value & $<3$ & $P<0.05$ & $<0.08$ & $>0.90$ & $>0.90$ & $>0.80$ & $>0.90$ & $<0.08$ \\
Measurement model & 2.43 & 0.005 & 0.07 & 0.94 & 0.93 & 0.89 & 0.97 & 0.06 \\
Structure model & 2.14 & 0.005 & 0.05 & 0.96 & 0.95 & 0.91 & 0.98 & 0.05 \\
\hline
\end{tabular}

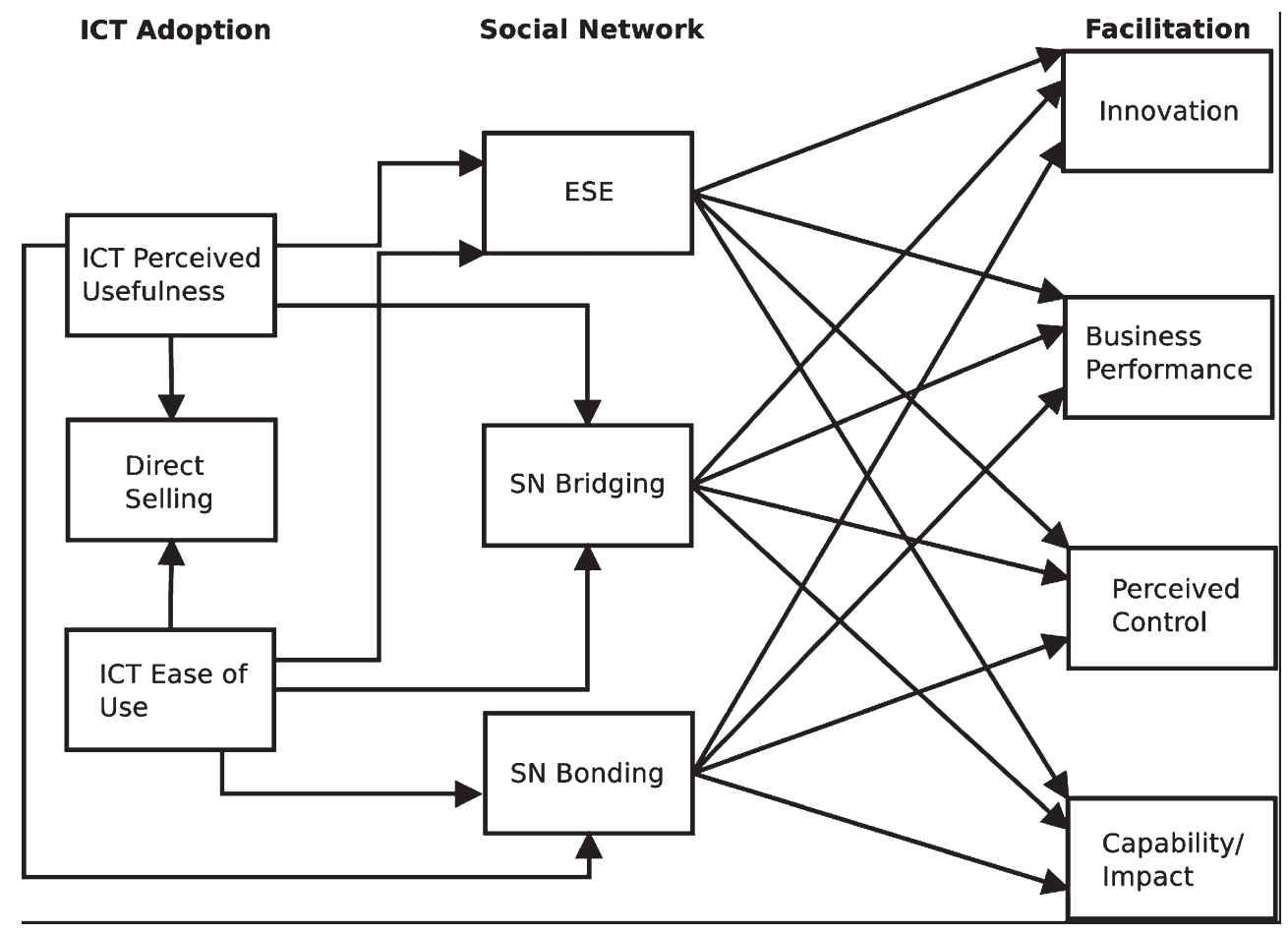

Fig. 3. Structural model.

social networking bonding was supported and in the right direction $(\beta=0.361, p<0.005)$. The relationship between ease of use of ICT use and bonding was supported and in the right direction $(\beta=0.613$, $p<0.005$ ).

The hypotheses $3 \mathrm{a}-3 \mathrm{~d}, 4 \mathrm{a}-4 \mathrm{~d}$ and $5 \mathrm{a}-5 \mathrm{~d}$ suggested that the social capital bonding and bridging will influence positively on multiple dimensions of empowerment. The path relationships between social networking $(\mathrm{SN})$ bridging and innovation facilitation in $\mathrm{H3a}(\beta=0.323, p<0.005)$, social networking $(\mathrm{SN})$ bridging and business performance facilitation in $\mathrm{H} 3 \mathrm{~b}(\beta=0.235, p<0.005)$, social networking (SN) bridging and perceived control facilitation in $\mathrm{H} 3 \mathrm{c}(\beta=0.214, p<0.005)$, and social networking (SN) bridging and capability facilitation in $\mathrm{H} 3 \mathrm{~d}$ $(\beta=0.523, p<0.005)$ were all positive and significant. Furthermore, the path relationships between social networking bonding and innovation facilitation in $\mathrm{H} 4 \mathrm{a}(\beta=0.691, p<0.005)$, social networking bonding and business performance facilitation in $\mathrm{H} 4 \mathrm{~b}$ ( $\beta=0.111, p<0.005)$, social networking bonding and perceived control in $\mathrm{H} 4 \mathrm{c}(\beta=0.423, p<0.005)$ and social networking bonding and capability facilitation in $\mathrm{H} 4 \mathrm{~d}(\beta=0.511, p<0.000)$ were also positive and significant.

In addition, the path relationships between entrepreneurial self-efficacy (ESE) and innovation facilitation in $\mathrm{H} 5 \mathrm{a} \quad(\beta=0.211, p<0.005)$, entrepreneurial self-efficacy and business performance facilitation in $\mathrm{H} 5 \mathrm{~b}(\beta=0.309, p<0.005)$, entrepreneurial self-efficacy (ESE) and perceived control facilitation in $\mathrm{H} 5 \mathrm{c}(\beta=0.412, p<0.000)$ and entrepreneurial self-efficacy and capability facilitation in $\mathrm{H} 5 \mathrm{~d}(\beta=0.401, p<0.005)$ were all positive and supported in this research (see Table 6). 
Table 6

Structural model analysis

\begin{tabular}{|c|c|c|c|}
\hline Hypotheses & Relationship & Estimates & t-value \\
\hline H1a & ICT Perceived Usefulness $\longrightarrow$ ICT use to support direct selling & 0.432 & $1.322 * *$ \\
\hline $\mathrm{H} 1 \mathrm{~b}$ & ICT ease of Use $\longrightarrow$ ICT use to support direct selling & 0.321 & $4.321 * *$ \\
\hline $\mathrm{H} 2 \mathrm{a}$ & ICT Perceived Usefulness $\longrightarrow$ entrepreneurial self-efficiency & 0.234 & $4.34 * * *$ \\
\hline $\mathrm{H} 2 \mathrm{~b}$ & ICT Perceived ease of use $\longrightarrow$ entrepreneurial self-efficiency & 0.121 & $7.12 * *$ \\
\hline $\mathrm{H} 2 \mathrm{c}$ & ICT adoption perceived usefulness $\longrightarrow$ social network bridging (moderated by ESE) & 0.342 & $11.57 * *$ \\
\hline $\mathrm{H} 2 \mathrm{~d}$ & ICT adoption perceived ease of use $\longrightarrow$ social network bridging (moderated by ESE) & 0.434 & $3.54 * *$ \\
\hline $\mathrm{H} 2 \mathrm{e}$ & ICT adoption perceived usefulness $\longrightarrow$ social network bonding (moderated by ESE) & 0.361 & $13.65 * *$ \\
\hline $\mathrm{H} 2 \mathrm{f}$ & ICT adoption perceived ease of use $\longrightarrow$ social network bonding (moderated by ESE) & 0.613 & $8.65 * *$ \\
\hline $\mathrm{H} 3 \mathrm{a}$ & SN bridging $\longrightarrow$ (facilitation) innovation & 0.323 & $9.33 * * *$ \\
\hline $\mathrm{H} 3 \mathrm{~b}$ & SN bridging $\longrightarrow$ (facilitation) business performance & 0.235 & $8.51 * *$ \\
\hline $\mathrm{H} 3 \mathrm{c}$ & SN bridging $\longrightarrow$ (facilitation) perceived control & 0.214 & $3.43 * *$ \\
\hline $\mathrm{H} 3 \mathrm{~d}$ & SN bridging $\longrightarrow$ (facilitation) capability & 0.523 & $5.49 * *$ \\
\hline $\mathrm{H} 4 \mathrm{a}$ & SN bonding $\longrightarrow$ (facilitation) innovation & 0.691 & $7.54 * *$ \\
\hline $\mathrm{H} 4 \mathrm{~b}$ & SN bonding $\longrightarrow$ (facilitation) business performance & 0.111 & $3.12 * *$ \\
\hline $\mathrm{H} 4 \mathrm{c}$ & SN bonding $\longrightarrow$ (facilitation) perceived control & 0.423 & $1.21 * *$ \\
\hline $\mathrm{H} 4 \mathrm{~d}$ & SN bonding $\longrightarrow$ (facilitation) capability/impact & 0.511 & $6.52 * * *$ \\
\hline H5a & Entrepreneurial self-efficacy $\longrightarrow$ (facilitation) innovation & 0.211 & $6.54 * *$ \\
\hline $\mathrm{H} 5 \mathrm{~b}$ & Entrepreneurial self-efficacy $\longrightarrow$ (facilitation) business performance & 0.309 & $14.33 * *$ \\
\hline $\mathrm{H} 5 \mathrm{c}$ & Entrepreneurial self-efficacy $\longrightarrow$ (facilitation) perceived control & 0.412 & $4.98 * * *$ \\
\hline $\mathrm{H} 5 \mathrm{~d}$ & Entrepreneurial self-efficacy $\longrightarrow$ (facilitation) capability/impact & 0.401 & $8.88 * *$ \\
\hline
\end{tabular}

\section{Discussion}

In this study, we investigated the facilitating role of information communication technology (ICT), entrepreneurial self-efficacy (ESE) and social networking (SN) for micro-entrepreneurs in Pakistan, to sustain lock-down during and after pandemic. The findings show that micro-entrepreneurs are creating and managing direct selling business by utilizing ICT tools and applications during COVID-19 pandemic. They joined social networking groups and communicated with customers through different apps, for the introduction and direct selling of their products. The ICT ease of use and usefulness significantly helped and facilitated them in growing their network. Furthermore, ICT positively affected direct selling of entrepreneurs with higher self-efficacy.

Our findings also suggest that ICT is useful for micro-entrepreneurs in Pakistan, especially in keeping them up to date via social networking. They can easily connect with customers at low cost through different applications such as Facebook, WhatsApp, Instagram and Twitter etc., which serve as enablers to initiate their transmission with both familiar and non-familiar customers. Furthermore, the entrepreneurial self-efficacy interplays between social network bridging and ICT use. A higher social network bridging is described by having higher entrepreneurial self-efficacy. The expanding access to opportunities, knowledge and community via ICT creates greater entrepreneurial self-efficacy to keep updated with direct selling circle.

During the special time of pandemic, bonding social network gives a closer look to an extent up to which micro-entrepreneurs can be facilitated and take advantage in direct selling from close contacts. They can receive rapid response from customers through social networking applications while entrepreneurial self-efficacy has a direct and profound effect between social network and ICT. We also observed higher social network bonding in micro-entrepreneurs with higher entrepreneurial self-efficacy and furthermore, direct selling is attributed to their social ties which they handle smartly $[25,85]$. In regard to the convenient features of facilitation, bridging social network has great sequel on innovation while bonding social network also has great effect on perceived control. Furthermore, social network bridging and bonding has significant effect on perceived control and provide micro-entrepreneurs freedom and control. 


\section{Implications of the study}

\subsection{Theoretical implications}

Moomal and Masrom studied the impact of information communication technology (ICT) on e-business in Pakistan and reported that deficiencies in business can be improved through innovative ICT technologies [29]. The authors in ref. [76] reported an empirical study which showed that information communication technology is a facilitator of innovation and improves business performance of enterprises in the developing countries. Sardar and co-authors also reported that innovative information communication technologies have started helping entrepreneurs in Pakistan [25].

This study is a significant contribution for entrepreneurial research during and after COVID19 pandemic in Pakistan. Technology Acceptance Model (TAM) is a widely accepted theoretical foundation which explores the acceptance of technology however, its use in terms of micro-entrepreneurs in Pakistan during COVID-19 is extremely limited and not studied at all. Our findings show that microentrepreneurs with high ESE have greater ability to use ICT tools and improve their business. In Pakistan, micro-entrepreneurs are already familiar with social-networking applications and use WhatsApp, Instagram and Facebook etc., which are user-friendly apps and require no professional training. The result is supported by the findings of Machikita and co-authors who found important positive correlations between the introduction of information communication technology and various indicators of performance of enterprises in other countries [86]. Our work provides detail understanding of the determinants for sustaining lock-down during COVID-19 pandemic. Micro-entrepreneurs need to shift to ICT technologies and bridge the gap of economic loss, which has been created.

\subsection{Practical implications}

From a practical point of view, the current research work shows that lock-downs (complete, partial and smart) have created difficulties for micro-entrepreneurs in direct selling, which resulted in economic loss and now they are struggling for survival. Direct selling in Pakistan creates multiple opportunities which contribute to both society and economy however, during the pandemic, opportunity creation has become extremely diffi- cult and every enterprise is struggling. In order to regain social and economic stability, ICT adoption with newly available technological infrastructure is mandatory or else micro-entrepreneurs will collapse. The findings indicated that entrepreneurs with good technological expertise and strong social networking ( $\mathrm{SN}$ ) background established more relationships with customers and grew their network. The entrepreneurial self-efficacy of entrepreneurs with ICT background was better than the other entrepreneurs. The struggling entrepreneurs should seek help from ICT solutions to grow networking and build entrepreneurial self-efficacy, for resolving currently faced business challenges. Furthermore, ICT adoption will provide an alternative to off-line selling during and after pandemic which will help micro-entrepreneurs in achieving their goals. In addition, their behaviour after pandemic will change from traditional selling to on-line selling which will create additional opportunities for them. The entrepreneurs should select an available ICT platform which improves their business and full-fill ease of use, or design new one to grow their business. The TAM analysis given in our work also supported these facts for growing or improving business.

\section{Limitations and future work}

The geographical constraint is an important limitation of current work which is inherent due to the nature of study and design methodology, as this work is centralized to micro-entrepreneurs of Pakistan. However, there is a possibility to extend this research work to other countries, to deeply understand the dynamics of ICT because COVID-19 not only hit micro-entrepreneurs of Pakistan but many other developing countries. The main context discussed here is related to sustaining lock-down during COVID-19 through the use of information communication technology (ICT) but it can be expanded to the performance of micro-entrepreneurs after COVID19. Another limitation of current work is sample size which is also inherent to the nature of study, as it was indeed tough to reach entrepreneurs who were struggling for survival.

\section{Conclusion}

This work adds to the conceptual and practical understanding of research on facilitation for 
the survival of microentrepreneurs, through information communication technology during and after the COVID-19 pandemic. It is evident from model analysis that the survival of microentrepreneurs is extremely necessary and can be achieved through information communication technology (ICT). TAM constructs testing showed that ICT is strong independent variable which plays an important role in affecting social capital building, bridging and self-efficacy, both directly and indirectly. The conceptual understanding of microentrepreneur's situation helped us distinguish ICT dimensions, social capital building and facilitation. The lock-downs have affected business in Pakistan and entrepreneurs are struggling for survival. During strict lock-down, traditional business was completely stopped. Although, the current work is restricted to two cities of Pakistan but in the future, it can be expanded to other cities to understand the impact of ICT on entrepreneurial behaviour. The impact of ICT on the facilitation of micro-entrepreneurs as described here can be used for future research work on social capital creation, self-efficacy building and empowerment. In addition, the empirical findings provide clear benefits of ICT for improving entrepreneurial self-efficacy in emerging economies such as Pakistan. On the basis of our findings, we recommend that entrepreneurial activity can be increased during and after lock-down which will ultimately help entrepreneurs in sustaining lock-down.

\section{Acknowledgments}

The authors would like to thank Prof. Jianqiu Zeng for his valuable suggestions.

\section{Author contributions}

CONCEPTION: Taiba Sardar and Zeng Jianqiu METHODOLOGY: Taiba Sardar and Zeng Jianqiu DATA COLLECTION: Taiba Sardar, Muhammad Bilal and Nausheen Syed

INTERPRETATION OR ANALYSIS OF DATA: Taiba Sardar, Muhammad Bilal and Nausheen Syed PREPARATION OF THE MANUSCRIPT: Taiba Sardar, Muhammad Bilal, Nausheen Syed and Zeng Jianqiu SUPERVISION: Zeng Jianqiu

\section{References}

[1] Worldometer. Coronavirus updates. COVID-19 Coronavirus pandemic. Coronavirus Cases. https://www. worldometers.info/coronavirus/ Accessed 15 June 2020.

[2] World Health Organization. Considerations for quarantine of individuals in the context of containment for coronavirus disease (COVID-19): interim guidance, 19 March 2020 (No. WHO/2019-nCoV/IHR Quarantine/2020.2). World Health Organization. 2020.

[3] World Health Organization. Critical preparedness, readiness and response actions for COVID-19-7 March 2020.

[4] The New York Times in Print for Tuesday, Feb. 25, 2020. (n.d.). The New York Times. Retrieved April 19, 2020, from https://www.nytimes.com/ issue/todayspaper/2020/02/25/todays-new-york-times.

[5] UNESCO. Half of world's student population not attending school: UNESCO launches global coalition to accelerate deployment of remote learning solutions. UNESCO. 19 March, 2020. https://en.unesco.org/news/half-worldsstudent-population-not-attending-school-unesco-launchesglobal-coalition-accelerate.

[6] Ogden T, Bull G. COVID-19: How Does Microfinance Weather the Current Storm. 2020. https://www.financial access.org/blog/2020/3/26/covid-19-howdoesmicrofinanceweather-the-current-storm.

[7] Sardar T, Jianqiu Z, Bing D, Mahmood W. Lurking influx of COVID-19 patients: From "Take it easy" to "What to do now" in Pakistan. OSF Preprints. 15 June, 2020.

[8] Cardona M, Kretschmer T, Strobel T. ICT and productivity: conclusions from the empirical literature. Information Economics and Policy. 2013;25(3):109-25.

[9] Brown W, Brown I. Next generation ICT policy in South Africa: Towards a human development-based ICT policy. InIFIP International Conference on Human Choice and Computers 2008 Sep 25 (pp. 109-123). Springer, Boston, MA.

[10] Majchrzak A, Markus ML, Wareham J. Designing for digital transformation: Lessons for information systems research from the study of ICT and societal challenges. MIS quarterly. 2016;40(2):267-77.

[11] Shahid A. Two coronavirus cases confirmed in Pakistan. Pakistan Today. 27 February, 2020.

[12] Ali I. Pakistan confirms first two cases of coronavirus, govt says "no need to panic". https://www.dawn. com/news/amp/1536792. Accessed 27 Feb 2020.

[13] Pakistan latest victim of coronavirus. https://www.geo. tv/latest/274482-pakistan-confirms-first. Accessed 7 Mar 2020.

[14] Malik K, Meki M, Morduch J, Ogden T, Quinn S, Said F. COVID-19 and the Future of Microfinance: Evidence and Insights from Pakistan. Oxford Review of Economic Policy, Forthcoming. 2020.

[15] Ayyagari M, Demirguc-Kunt A, Maksimovic V. Small vs. young firms across the world: contribution to employment, job creation, and growth. World Bank Policy Research Working Paper, No. 5631, World Bank. 2011.

[16] Jamak AB, Ali RM, Ghazali Z. A breakout strategy model of Malay (Malaysian indigenous) micro-entrepreneurs. Procedia-Social and Behavioral Sciences. 2014;109(0): 572-83. 
[17] Kureshi NI, Mann R, Khan MR, Qureshi MF. Quality management practices of SME in developing countries: A survey of manufacturing SME in Pakistan. Journal of Quality and Technology Management. 2009;5(2):63-89.

[18] Kundi GM, Shah B. eBusiness in Pakistan: opportunities and threats. The Journal of Internet Banking and Commerce. 1970;12(3):1-23.

[19] Kossai M, Piget P. Adoption of information and communication technology and firm profitability: Empirical evidence from Tunisian SMEs. The Journal of High Technology Management Research. 2014;25(1):9-20.

[20] Black SE, Lynch LM. What's driving the new economy?: The benefits of workplace innovation. The Economic Journal. 2004;114(493):F97-116.

[21] Bloom N, Draca M, Kretschmer T, Sadun R, Overman H, Schankerman M. The economic impact of ICT. Centre for Economic Performance, LSE, SMART N. 2007/0020. 2010.

[23] Brynjolfsson E, Hitt LM. Computing productivity: Firmlevel evidence. Working papers 4210-01. Massachusetts Institute of Technology (MIT). Sloan School of Management. 2004.

[23] Caroli E, Van Reenen J. Skill-biased organizational change? Evidence from a panel of British and French establishments. The Quarterly Journal of Economics. 2001;116(4):1449-92.

[24] OECD. Science, technology and industry scoreboard 2009. Paris: OECD. 2009

[25] Sardar T, Jianqiu Z, Bilal M, Akram Z, Shahzad K. Revolution of ICT: Women entrepreneurs in Pakistan. Human Systems Management. 2019;38(4):357-64.

[26] Davis FD. Perceived usefulness, perceived ease of use, and user acceptance of information technology. MIS quarterly. 1989;13(3):319-40.

[27] Venkatesh V, Thong JY, Xu X. Unified theory of acceptance and use of technology: A synthesis and the road ahead. Journal of the Association for Information Systems. 2016;17(5):328-76.

[28] Naivinit S. Gender, access to community telecenter and livelihood asset changes. Journal of Information, Communication and Ethics in Society. 2009;7(2-3):128-35.

[29] Moomal A, Masrom M. ICT Development and Its Impact on e-Business and HRM Strategies in the Organizations of Pakistan. Journal of Advanced Management Science. 2015;3(4):344-9.

[30] Maidment J, Macfarlane S. Craft groups: Sites of friendship, empowerment, belonging and learning for older women. Groupwork: an Interdisciplinary Journal for Working With Groups. 2009;19(1):10-25.

[31] Wilding R. Refugee youth, social inclusion, and ICT's: Can good intentions go bad? Journal of Information, Communication and Ethics in Society. 2009;7(2/3):159-74.

[32] Kundi GM, Shah B. IT in Pakistan: Threats \& opportunities for eBusiness. The Electronic Journal of Information Systems in Developing Countries. 2009;36(1): $1-31$.

[33] Zafar J. E-Human Resource Management: A case study of the State Bank in Pakistan (Doctoral dissertation, Universiti Utara Malaysia).

[34] Donath J, Boyd D. Public displays of connection. BT Technology Journal. 2004;22(4):71-82.
[35] Rauniar R, Rawski G, Johnson B, Yang J. Social media user satisfaction-theory development and research findings. Journal of Internet Commerce. 2013;12(2): 195-224.

[36] Malone TW, Yates J, Benjamin RI. Electronic markets and electronic hierarchies. Communications of the ACM. 1987;30(6):484-97.

[37] Rahman SA, Taghizadeh SK, Ramayah T, Alam MM. Technology acceptance among micro-entrepreneurs in a marginalized social strata: The case of social innovation in Bangladesh. Technological Forecasting and Social Change. 2017;118:236-45.

[38] Bargh JA, McKenna KY. The Internet and social life. Annu Rev Psychol. 2004;55:573-90.

[39] Solow RM. We'd better watch out. New York Times Book Review. 1987;36.

[40] Hollenstein H. Determinants of the adoption of Information and Communication Technologies (ICT): An empirical analysis based on firm-level data for the Swiss business sector. Structural Change and Economic Dynamics. 2004;15(3):315-42

[41] Javed A, Yasir M, Ali M, Majid A. ICT-enabled innovation, enterprise value creation and the rise of electronic social enterprise. World Journal of Entrepreneurship, Management and Sustainable Development. 2020 May 5.

[42] Bvuma S, Marnewick C. Sustainable Livelihoods of Township Small, Medium and Micro Enterprises towards Growth and Development. Sustainability. 2020;12(8):3149, pp. 1-17.

[43] Rauniar R, Rawski G, Johnson B, Yang J. Social media user satisfaction-theory development and research findings. Journal of Internet Commerce. 2013;12(2): 195-224.

[44] Agnihotri R, Kothandaraman P, Kashyap R, Singh R. Bringing "social" into sales: The impact of salespeople's social media use on service behaviors and value creation. Journal of Personal Selling \& Sales Management. 2012;32(3): 333-48.

[45] Crittenden VL, Crittenden WF, Ajjan H. Empowering women micro-entrepreneurs in emerging economies: The role of information communications technology. Journal of Business Research. 2019;98:191-203.

[46] Bidwell NJ, Robinson S, Vartiainen E, Jones M, Siya MJ, Reitmaier T, Marsden G, Lalmas M. Designing social media for community information sharing in rural South Africa. In Proceedings of the Southern African Institute for Computer Scientist and Information Technologists Annual Conference 2014 on SAICSIT 2014 Empowered by Technology 2014 Sep 29 (pp. 104-114).

[47] Beninger S, Ajjan H, Mostafa RB, Crittenden VL. A road to empowerment: social media use by women entrepreneurs in Egypt. International Journal of Entrepreneurship and Small Business. 2016;27(2-3):308-32.

[48] Davis FD, Bagozzi RP, Warshaw PR. User acceptance of computer technology: a comparison of two theoretical models. Management Science. 1989;35(8):982-1003.

[49] Venkatesh V. Determinants of perceived ease of use: Integrating control, intrinsic motivation, and emotion into the technology acceptance model. Information Systems Research. 2000;11(4):342-65. 
[50] Pontiggia A, Virili F. Network effects in technology acceptance: Laboratory experimental evidence. International Journal of Information Management. 2010;30(1):68-77.

[51] Zhou T, Lu Y, Wang B. Integrating TTF and UTAUT to explain mobile banking user adoption. Computers in Human Behavior. 2010;26(4):760-7.

[52] Bandura A. Self-efficacy: toward a unifying theory of behavioral change. Psychological Review. 1977;84(2): 191-215.

[53] Saleem H, Beaudry A, Croteau AM. Antecedents of computer self-efficacy: A study of the role of personality traits and gender. Computers in Human Behavior. 2011;27(5):1922-36.

[54] McGee JE, Peterson M, Mueller SL, Sequeira JM. Entrepreneurial self-efficacy: Refining the measure. Entrepreneurship Theory and Practice. 2009;33(4): 965-88.

[55] Drnovšek M, Wincent J, Cardon MS. Entrepreneurial self-efficacy and business start-up: developing a multi-dimensional definition. International Journal of Entrepreneurial Behavior \& Research. 2010;16(4): 329-48.

[56] Zhao H, Seibert SE. The big five personality dimensions and entrepreneurial status: A meta-analytical review. Journal of Applied Psychology. 2006;91(2):259-71.

[57] Chebat JC, Kollias P. The impact of empowerment on customer contact employees' roles in service organizations. Journal of Service Research. 2000;3(1):66-81.

[58] Marcolin BL, Compeau DR, Munro MC, Huff SL. Assessing user competence: Conceptualization and measurement. Information Systems Research. 2000;11(1):37-60.

[59] Goodhue DL, Thompson RL. Task-technology fit and individual performance. MIS Quarterly. 1995:213-36.

[60] Batjargal B. Social capital and entrepreneurial performance in Russia: A longitudinal study. Organization Studies. 2003;24(4):535-56.

[61] Kadam A, Ayarekar S. Impact of Social Media on Entrepreneurship and Entrepreneurial Performance: Special Reference to Small and Medium Scale Enterprises. SIES Journal of Management. 2014;10(1):3-11.

[62] Smith PR, Taylor J. Marketing communications: an integrated approach. Kogan Page Publishers; 2004.

[63] Jagongo A, Kinyua C. The social media and entrepreneurship growth. International Journal of Humanities and Social Science. 2013;3(10):213-27.

[64] Mukoolwe E, Korir J. Social Media and Entrepreneurship: Tools, benefits and challenges: A case study of women Online Entrepreneurs on Kilimani Mums Marketplace on Facebook. International Journal of Humanities and Social Sciences. 2016;6:248-56.

[65] Perju-Mitran A, Budacia AE. Gender differences in modeling the influence of online marketing communication on behavioral intentions. Procedia Economics and Finance. 2015;27:567-73.

[66] Tosifyan M, Tosifyan S. A Research on the effect of social media on tendency to entrepreneurship and business establishment (Case Study: Active Iranian Entrepreneurs in Social Media). Emerging Science Journal. 2017;1(1): 43-8.
[67] Park JY, Sung CS, Im I. Does social media use influence entrepreneurial opportunity? A review of its moderating role. Sustainability. 2017;9(9):1593, pp. 1-16.

[68] Kaplan AM, Haenlein M. Users of the world, unite! The challenges and opportunities of Social Media. Business Horizons. 2010;53(1):59-68.

[69] Coleman JS. Social capital in the creation of human capital. American Journal of Sociology. 1988;94:S95-120.

[70] Stam W, Arzlanian S, Elfring T. Social capital of entrepreneurs and small firm performance: A meta-analysis of contextual and methodological moderators. Journal of Business Venturing. 2014;29(1):152-73.

[71] Brynjolfsson E, Hitt LM. Beyond computation: Information technology, organizational transformation and business performance. Journal of Economic Perspectives. 2000;14(4):23-48.

[72] Lyytinen K, Newman M. Explaining information systems change: a punctuated socio-technical change model. European Journal of Information Systems. 2008;17(6): 589-613.

[73] Aguilera EL, Cuevas-Vargas H, González AM. The impact of information and communication technologies on the competitiveness: Evidence of manufacturing SMEs in Aguascalientes, Mexico. International Review of Management and Business Research. 2015;4(3):758-70.

[74] Ongori H, Migiro SO. Information and communication technologies adoption in SMEs: literature review. Journal of Chinese Entrepreneurship. 2010;2:93-104.

[75] Dieweri WE, Smith AM. Productivity measurement for a distribution firm. Journal of Productivity Analysis. 1994;5(4):335-47.

[76] Cuevas-Vargas H, Enríquez LA, Adame MG, Servin JL. The use of ICTs and its relation with the competitiveness of Mexican SMEs. European Scientific Journal. 2015;11(13):294-310.

[77] Klein R. An empirical examination of patient-physician portal acceptance. European Journal of Information Systems. 2007;16(6):751-60.

[78] Hess TJ, McNab AL, Basoglu KA. Reliability generalization of perceived ease of use, perceived usefulness, and behavioral intentions. Mis Quarterly. 2014;38(1): $1-28$.

[79] Menon S. Employee empowerment: An integrative psychological approach. Applied Psychology. 2001;50(1): 153-80.

[80] Madrid-Guijarro A, Garcia D, Van Auken H. Barriers to innovation among Spanish manufacturing SMEs. Journal of Small Business Management. 2009;47(4):465-88.

[81] Ellison NB, Steinfield C, Lampe C. The benefits of Facebook "friends:" Social capital and college students' use of online social network sites. Journal of Computer-Mediated Communication. 2007;12(4):1143-68.

[82] Beninger S, Ajjan H, Mostafa RB, Crittenden VL. A road to empowerment: social media use by women entrepreneurs in Egypt. International Journal of Entrepreneurship and Small Business. 2016;27(2-3):308-32.

[83] Hair Jr JF, Hult GT, Ringle C, Sarstedt M. A primer on partial least squares structural equation modeling (PLS-SEM) Sage Publications. Thousand Oaks, CA, USA. 2016. 
[84] Fornell C, Larcker DF. Evaluating structural equation models with unobservable variables and measurement error. Journal of Marketing Research. 1981;18(1):39-50.

[85] Howard PE, Rainie L, Jones S. Days and nights on the Internet: The impact of a diffusing technology. American Behavioral Scientist. 2001;45(3):383-404.
[86] Machikita T, Tsuji M, Ueki Y. How ICTs raise manufacturing performance: Firm-level evidence in Southeast Asia. Economic Research Institute for ASEAN and East Asia papers DP-2010-07. 2010. 